\title{
Neuropsychiatric Manifestations in Mild Cognitive Impairment: A Systematic Review of the Literature
}

\author{
Liana G. Apostolova ${ }^{a, b}$ Jeffrey L. Cummings ${ }^{a, c}$ \\ ${ }^{a}$ Department of Neurology, ${ }^{b}$ Laboratory of Neuro Imaging, and ${ }^{\mathrm{C}}$ Department of Psychiatry and \\ Biobehavioral Sciences, David Geffen School of Medicine, UCLA, Los Angeles, Calif., USA
}

\section{Key Words}

Neuropsychiatric symptoms · Behavior · Mild cognitive impairment, early symptoms

\begin{abstract}
Background: Mild cognitive impairment $(\mathrm{MCl})$ is an etiologically heterogeneous condition that is characterized by cognitive changes without impairment of activities of daily living and insufficient to represent dementia. $\mathrm{MCl}$ is an important risk state for dementia. Neuropsychiatric symptoms may be present in $\mathrm{MCl}$. Methods: We executed a PubMed search for articles on the neuropsychiatric manifestations in $\mathrm{MCl}$ and reviewed their findings. Results: Behavioral abnormalities are reported in $35-75 \%$ of $\mathrm{MCl}$ patients with the most common being depression, apathy, anxiety and irritability. The observed variability in symptom prevalence can be explained by the different sampling methods, $\mathrm{MCl}$ diagnostic criteria and behavioral instruments used. There is a compelling body of evidence that $\mathrm{MCl}$ patients with behavioral features are more prone to develop Alzheimer's disease (AD) than patients without these features. Conclusions: Neuropsychiatric symptoms are common features of $\mathrm{MCl}$. The behavioral changes observed in $\mathrm{MCl}$ are similar to those of $A D$ and may help identify the subgroup of $\mathrm{MCl}$ patients with prodromal AD. Large prospective longitudinal studies would greatly contribute to our understanding of the epidemiology, diagnostic and prognostic value of the neuropsychiatric features in $\mathrm{MCl}$.

Copyright $\odot 2007$ S. Karger AG, Basel
\end{abstract}

\section{Introduction}

Mild cognitive impairment (MCI) is a heterogeneous condition with cognitive characteristics between normal aging and dementia. It is currently defined as a syndrome with impairment of memory or another cognitive deficit that does not interfere substantially with personal affairs nor result in inability to live independently [1]. Its most common etiology is Alzheimer's disease (AD), other etiologies including dementia with Lewy bodies, vascular or frontotemporal dementia [2]. Not all patients with MCI progress to dementia and some recover to normal cognition [3].

Neuropsychiatric symptoms may accompany MCI and assist in identifying incipient dementia. Thus behavioral abnormalities may prove to be a valuable biomarker for impending dementia. In this review we summarize the evidence on neuropsychiatric manifestations in MCI.

\section{Methodology}

Study Design

We summarize the findings of the studies of neuropsychiatric features of MCI from the English literature published before December 2006. We included studies that provided a description of the MCI diagnostic criteria used, described the means of collecting behavioral data and had a minimum MCI patient sample of 20. Using the PubMed search engine we found 21 peer-reviewed

\section{KARGER \\ Fax +41613061234 \\ E-Mail karger@karger.ch}

www.karger.com
(C) 2007 S. Karger AG, Basel

Accessible online at:

www.karger.com/dem
Liana G. Apostolova, MD

Alzheimer's Disease Research Center

10911 Weyburn, 2nd floor

Los Angeles, CA 90095 (USA)

Tel. +1 310794 2551, Fax +1 310794 3148,E-Mail lapostolova@mednet.ucla.edu 
Table 1. Characteristics of each study included in this review

\begin{tabular}{|c|c|c|c|c|c|}
\hline Author/year & Design & Setting & MCI criteria & Behavioral instrument & MCI at baseline, $n$ \\
\hline $\begin{array}{l}\text { Barnes } \\
\text { et al. [13] }\end{array}$ & longitudinal & population-based & $\begin{array}{l}\geq 1.5 \text { SD below AEAN on standard } \\
\text { neuropsychological tests }\end{array}$ & CES-D & $\begin{array}{l}\text { none } \\
\text { (296 at follow-up) }\end{array}$ \\
\hline $\begin{array}{l}\text { Chan } \\
\text { et al. [12] }\end{array}$ & cross-sectional & population-based & $\begin{array}{l}\geq 1.5 \text { SD on one test or } \geq 1 \text { SD on two } \\
\text { or more tests below AEAN on } \\
\text { standard neuropsychological tests }\end{array}$ & $\begin{array}{l}\text { NPI } \\
\text { BSRS }\end{array}$ & 133 \\
\hline Copeland et al. [29] & longitudinal & population-based & $\mathrm{CDR}=0.5$ & semistructured interview & 165 \\
\hline $\begin{array}{l}\text { Kumar } \\
\text { et al. [8] }\end{array}$ & cross-sectional & population-based & clinical & $\begin{array}{l}\text { Goldberg Anxiety and } \\
\text { Goldberg Depression } \\
\text { Scales, DSM-IV }\end{array}$ & 29 \\
\hline $\begin{array}{l}\text { Kumar } \\
\text { et al. [9] }\end{array}$ & cross-sectional & population-based & clinical & $\begin{array}{l}\text { Goldberg Anxiety and } \\
\text { Goldberg Depression } \\
\text { Scales, DSM-IV }\end{array}$ & 29 \\
\hline Lam et al. [26] & cross-sectional & population-based & $\mathrm{CDR}=0.5$ & NPI & 195 \\
\hline $\begin{array}{l}\text { Lyketsos } \\
\text { et al. [16] }\end{array}$ & cross-sectional & population-based & $\begin{array}{l}\geq 1.5 \text { SD below AEAN on standard } \\
\text { neuropsychological tests }\end{array}$ & NPI & 320 \\
\hline $\begin{array}{l}\text { Feldman } \\
\text { et al. [4] }\end{array}$ & cross-sectional & clinical trial & $\begin{array}{l}\mathrm{CDR}=0.5 \text { and impaired performance } \\
\text { on NYU delayed paragraph recall }\end{array}$ & NPI & 1,010 \\
\hline Geda et al. [7] & cross-sectional & tertiary center & clinical & NPI & 54 \\
\hline Geda et al. [6] & longitudinal & tertiary center & clinical & GDS & $\begin{array}{l}\text { none } \\
\text { (40 at follow-up) }\end{array}$ \\
\hline $\begin{array}{l}\text { Hwang } \\
\text { et al. [14] }\end{array}$ & cross-sectional & tertiary center & $\begin{array}{l}\geq 1.5 \text { SD below AEAN on standard } \\
\text { neuropsychological tests }\end{array}$ & NPI & 28 \\
\hline $\begin{array}{l}\text { Gabryelewicz } \\
\text { et al. [25] }\end{array}$ & longitudinal & tertiary center & clinical and $\mathrm{CDR}=0.5$ & MADRS & 105 \\
\hline $\begin{array}{l}\text { Gabryelewicz } \\
\text { et al. [24] }\end{array}$ & longitudinal & tertiary center & clinical and $\mathrm{CDR}=0.5$ & MADRS, DSM-IV & 102 \\
\hline Li et al. [19] & longitudinal & tertiary center & $\begin{array}{l}\text { cognitive capacity screening examina- } \\
\text { tion or MMSE scores between } 24 \text { and } 26\end{array}$ & HDRS & 21 \\
\hline $\begin{array}{l}\text { Lopez } \\
\text { et al. [15] }\end{array}$ & cross-sectional & tertiary center & $\begin{array}{l}\geq 1.5 \text { SD below AEAN on standard } \\
\text { neuropsychological tests }\end{array}$ & CBRSD & 228 \\
\hline $\begin{array}{l}\text { Modrego and } \\
\text { Ferrández [10] }\end{array}$ & longitudinal & tertiary center & clinical & DSM-IV, GDS & 114 \\
\hline Ready et al. [11] & cross-sectional & tertiary center & clinical & FrSBe & 20 \\
\hline $\begin{array}{l}\text { Robert } \\
\text { et al. }[21,22]\end{array}$ & longitudinal & tertiary center & $\begin{array}{l}<2 / 3 \text { on delayed recall on MMSE or } \\
\text { Isaac set test }<29\end{array}$ & $\begin{array}{l}\text { MADRS, } \\
\text { Goldberg Anxiety Scale, } \\
\text { Apathy Inventory }\end{array}$ & 226 \\
\hline $\begin{array}{l}\text { Robert } \\
\text { et al. }[21,22]\end{array}$ & longitudinal & tertiary center & $\begin{array}{l}<2 / 3 \text { on delayed recall on MMSE or } \\
\text { Isaac set test }<29\end{array}$ & Apathy Inventory & 145 \\
\hline $\begin{array}{l}\text { Wilkosz } \\
\text { et al. [17] }\end{array}$ & longitudinal & tertiary center & $\begin{array}{l}\geq 1.5 \text { SD below AEAN on standard } \\
\text { neuropsychological tests }\end{array}$ & CBRSD & 49 \\
\hline
\end{tabular}

AEAN = Age- and education-adjusted norms; BSRS = Behavior Symptom Rating Scale; CDR = Clinical Dementia Rating Scale; CBRSD = Consortium to Establish a Registry for Alzheimer's Disease Behavioral Rating Scale for Dementia; CES-D = Center for Epidemiological Studies Depression Scale; DSM = Diagnostic and Statistical
Manual of Mental Disorders; FrSBe = Frontal Systems Behavior Scale; GDS $=$ Geriatric Depression Scale; HDRS $=$ Hamilton Depression Rat ing Scale; MADRS = Montgomery-Asberg Depression Rating Scale; MMSE = Mini-Mental State Examination; NPI = Neuropsychiatric Inventory; NYU = New York University; SD = standard deviation. 
Table 2. Neuropsychiatric instruments used by studies included in this review

\begin{tabular}{|c|c|c|c|c|c|}
\hline Instrument & Behaviors evaluated & Administration & $\begin{array}{l}\text { Time } \\
\text { required }\end{array}$ & $\begin{array}{l}\text { Developed } \\
\text { for the } \\
\text { elderly }\end{array}$ & $\begin{array}{l}\text { Developed } \\
\text { for } \\
\text { dementia }\end{array}$ \\
\hline Apathy inventory & apathy & $\begin{array}{l}\text { trained examiner interviews subject and } \\
\text { caregiver separately }\end{array}$ & & yes & yes \\
\hline BSRS & $\begin{array}{l}\text { several neuropsychiatric } \\
\text { behaviors }\end{array}$ & $\begin{array}{l}\text { trained examiner interviews } \\
\text { caregiver }\end{array}$ & $10-15 \mathrm{~min}$ & yes & yes \\
\hline CBRSD & $\begin{array}{l}\text { wide range of neuro- } \\
\text { psychiatric behaviors }\end{array}$ & trained examiner interviews subject & $20-30 \mathrm{~min}$ & yes & yes \\
\hline CES-D & depression & self-administered & $5 \mathrm{~min}$ & yes & no \\
\hline DSM-III/IV & $\begin{array}{l}\text { diagnostic guidelines for } \\
\text { major and minor depression }\end{array}$ & N/A & N/A & no & no \\
\hline FrSBe & apathy, disinhibition & self-administered part and informant part & & no & no \\
\hline $\begin{array}{l}\text { Goldberg } \\
\text { anxiety scale }\end{array}$ & anxiety & self-administered & $5 \mathrm{~min}$ & no & no \\
\hline $\begin{array}{l}\text { Goldberg } \\
\text { depression scale }\end{array}$ & depression & self-administered & $5 \mathrm{~min}$ & no & no \\
\hline GDS & depression & self-administered & $5-10 \mathrm{~min}$ & yes & no \\
\hline HDRS & depression & trained examiner interviews subject & $20-30 \mathrm{~min}$ & no & no \\
\hline MADRS & depression & trained examiner interviews subject & $20 \min$ & no & no \\
\hline $\begin{array}{l}\text { Semistructured } \\
\text { interview }\end{array}$ & $\begin{array}{l}\text { psychosis, depression, } \\
\text { passive behavior, agitation }\end{array}$ & $\begin{array}{l}\text { trained examiner interviews subject } \\
\text { and/or caregiver }\end{array}$ & & yes & yes \\
\hline NPI & $\begin{array}{l}\text { wide range of neuro- } \\
\text { psychiatric behaviors }\end{array}$ & trained examiner interviews caregiver & $10-15 \mathrm{~min}$ & yes & yes \\
\hline
\end{tabular}

For abbreviations see table 1 .

original studies that met our criteria (table 1). Eight were population-based studies (6 cross-sectional and 2 longitudinal) and 12 used convenience samples from tertiary memory disorder clinics and research databases (5 cross-sectional and 7 longitudinal). One publication described the baseline behavioral data from a large international multicenter clinical trial [4]. These three sources provide variable estimates of behavioral symptom prevalence in MCI, likely reflecting the selection biases involved in the sampling method, e.g. tertiary center studies tend to report higher frequencies of neuropsychiatric abnormalities as subjects with behavioral abnormalities are referred more readily from the primary care network (table 2). All three sources lend valuable types of information.

\section{Diagnostic Criteria for MCI}

These 21 studies have used several different sets of criteria for the diagnosis of MCI (table 1). Some have relied on the original clinical criteria of Petersen et al. [5] where MCI is defined as memory complaint preferably corroborated by an informant, impaired memory on clinical assessment and preserved activities of daily living, and failing to meet criteria for dementia [6-11]. Others have supplemented the original Petersen criteria with a neuropsychological cutoff - commonly 1.0 [12] or 1.5 SD [12-17] from the age- and education-adjusted normative scores on selected neuropsychological tests. Yet others $[18,19]$ have used the Mini-Mental State Examination (MMSE) score [20], or the MMSE memory subscore in conjunction with the Isaacs-set test [21,22], a Clinical Dementia Rating scale (CDR) [23] score of 0.5 [24-26], or a combination of the New York University delayed paragraph recall test and a CDR score of 0.5 [4]. This heterogeneity in diagnostic criteria undoubtedly contributes to the variability in prevalence and incidence data on neuropsychiatric symptoms in MCI. For example studies that use an inclusion criterion of cognitive performance 1 SD or more below the age- and education-adjusted norms on a neuropsychological test will have a less cognitively impaired MCI cohort relative to those that use the 1.5 SD cutoff. This may affect the prevalence of behavioral symptoms [27].

The presence of untreated depression in MCI subjects was an exclusion criterion in some studies [6, 7, 24, 25]. Depression, a common behavioral presentation in MCI (table 3), frequently coexists with other behavioral symptoms [28]. Thus excluding depressed MCI patients from entry into studies of behavioral abnor- 
Table 3. Rates of neuropsychiatric symptoms reported by studies included in this review

\begin{tabular}{|c|c|c|c|}
\hline $\begin{array}{l}\text { Neuropsychiatric } \\
\text { symptom }\end{array}$ & Study type & $\begin{array}{l}\text { Reported } \\
\text { prevalence, \% }\end{array}$ & Behavioral measure [citation] \\
\hline Any NPI symptom & $\begin{array}{l}\text { population-based } \\
\text { clinical trial } \\
\text { tertiary center }\end{array}$ & $\begin{array}{l}43 \\
59 \\
35-75\end{array}$ & $\begin{array}{l}\text { NPI }[16] \\
\text { NPI }[4] \\
\text { NPI }[7,14]\end{array}$ \\
\hline Depression & $\begin{array}{l}\text { clinical trial } \\
\text { tertiary center }\end{array}$ & $\begin{array}{l}16-20 \\
11 \\
3 \text { (minor) } \\
17 \text { (major) } \\
3 \\
43-46 \\
45 \\
9-39 \\
53 \\
29 \\
27 \text { (minor) } \\
9-20 \text { (major) } \\
36\end{array}$ & $\begin{array}{l}\text { NPI }[12,16] \\
\text { DSM-III-R [18] } \\
\text { DSM-IV }[8,9] \\
\text { Goldberg Depression Scale [8] } \\
\text { semistructured interview [29] } \\
\text { NPI [4] } \\
\text { NPI [7, 14] } \\
\text { CERAD Behavioral Rating Scale [15] } \\
\text { HDRS [19] } \\
\text { DSM-IV [10, 24, 25] } \\
\text { GDS [10] }\end{array}$ \\
\hline Apathy & $\begin{array}{l}\text { population-based } \\
\text { clinical trial } \\
\text { tertiary center }\end{array}$ & $\begin{array}{l}32 \\
13.3-27.3 \\
37 \\
11-39 \\
40\end{array}$ & $\begin{array}{l}\text { NPI [16] } \\
\text { semistructured interview [29] } \\
\text { NPI [4] } \\
\text { NPI [7, 14] } \\
\text { CERAD Behavioral Rating Scale [15] }\end{array}$ \\
\hline Anxiety & $\begin{array}{l}\text { population-based } \\
\text { clinical trial } \\
\text { tertiary center }\end{array}$ & $\begin{array}{l}10 \\
10 \\
3 \\
45 \\
11-25 \\
49 \\
3\end{array}$ & $\begin{array}{l}\text { NPI [16] } \\
\text { DSM-III-R [18] } \\
\text { Goldberg Anxiety Scale [8] } \\
\text { NPI [4] } \\
\text { NPI [7, 14] } \\
\text { CERAD Behavioral Rating Scale [15] } \\
\text { Goldberg Anxiety Scale [21] }\end{array}$ \\
\hline Delusions & $\begin{array}{l}\text { population-based } \\
\text { clinical trial } \\
\text { tertiary center }\end{array}$ & $\begin{array}{l}3 \\
6 \\
0-4 \\
14\end{array}$ & $\begin{array}{l}\text { NPI }[16] \\
\text { NPI }[4] \\
\text { NPI }[7,14] \\
\text { CERAD Behavioral Rating Scale }[15]\end{array}$ \\
\hline Hallucinations & $\begin{array}{l}\text { population-based } \\
\text { clinical trial } \\
\text { tertiary center }\end{array}$ & $\begin{array}{l}1 \\
2 \\
0 \\
4\end{array}$ & $\begin{array}{l}\text { NPI }[16] \\
\text { NPI }[4] \\
\text { NPI }[7,14] \\
\text { CERAD Behavioral Rating Scale }[15]\end{array}$ \\
\hline Disinhibition & $\begin{array}{l}\text { population-based } \\
\text { clinical trial } \\
\text { tertiary center }\end{array}$ & $\begin{array}{r}3 \\
10 \\
0 \\
4\end{array}$ & $\begin{array}{l}\text { NPI }[16] \\
\text { NPI }[4] \\
\text { NPI }[7,14] \\
\text { CERAD Behavioral Rating Scale }[15]\end{array}$ \\
\hline Agitation & $\begin{array}{l}\text { population-based } \\
\text { clinical trial } \\
\text { tertiary center }\end{array}$ & $\begin{array}{l}11 \\
25 \\
18-36 \\
35 \\
4-18 \\
38\end{array}$ & $\begin{array}{l}\text { NPI [16] } \\
\text { Behavior Symptom Rating Scale [12] } \\
\text { semistructured interview [29] } \\
\text { NPI [4] } \\
\text { NPI }[7,14] \\
\text { CERAD Behavioral Rating Scale [15] }\end{array}$ \\
\hline Euphoria & $\begin{array}{l}\text { population-based } \\
\text { clinical trial } \\
\text { tertiary center }\end{array}$ & $\begin{array}{l}1 \\
5 \\
0\end{array}$ & $\begin{array}{l}\text { NPI }[16] \\
\text { NPI }[4] \\
\text { NPI }[7,14]\end{array}$ \\
\hline
\end{tabular}


Table 3 (continued)

\begin{tabular}{llll}
\hline $\begin{array}{l}\text { Neuropsychiatric } \\
\text { symptom }\end{array}$ & Study type & $\begin{array}{l}\text { Reported } \\
\text { prevalence, } \%\end{array}$ & Behavioral measure [citation] \\
\hline Irritability & $\begin{array}{l}\text { population-based } \\
\text { clinical trial }\end{array}$ & 15 & NPI [16] \\
& tertiary center & 24 & NPI [4] \\
& population-based & 4 & NPI [7, 14] \\
Aberrant motor & clinical trial & 8 & NPI [16] \\
behavior & tertiary center & 0 & NPI [4] \\
& & & NPI [7, 14] \\
\hline
\end{tabular}

For abbreviations see table 1 .

malities in MCI may alter the prevalence not only of depression itself but also of a host of other noncognitive symptoms.

\section{Subtypes}

MCI has two major subtypes - the amnestic type characterized by impaired memory and the nonamnestic type characterized by preserved memory in the presence of impairment of another cognitive domain. Among the 21 studies included in this review 2 population-based studies focused on amnestic MCI [8, 9], 3 included both amnestic and nonamnestic MCI $[13,16,18]$ and 3 did not provide this information $[12,26,29]$. Of the tertiary center studies, 7 focused on amnestic MCI [7, 10, 11, 14, 19, 21, 22] and 4 also included nonamnestic MCI subjects [15, 17, 24, 25]. Only 2 studies compared the single domain amnestic to the multiple domain (amnestic and nonamnestic) MCI [15, 24]. The distinction of which behavioral abnormalities occur in amnestic versus nonamnestic MCI may be valuable and offer prognostic information as there is preliminary evidence that amnestic MCI patients convert to AD more commonly than do nonamnestic MCI patients [30].

\section{Methods of Neuropsychiatric Symptom Ascertainment}

The studies included in this review have used several different instruments for neuropsychiatric assessment (table 2). Some test a broad variety of behavioral abnormalities while others focus on only one. Five used tools developed for the elderly population; 4 of these were developed specifically for subjects with dementia. Some instruments are administered to the patient, the caregiver or both while others are self-administered. The most commonly used instrument (6 studies) was the Neuropsychiatric Inventory (NPI) [31].

\section{Results}

Neuropsychiatric symptoms are very common in MCI. The most comprehensive studies of behavioral manifestations have documented at least one neuropsychiatric symptom in $35-75 \%$ of MCI patients (table 3). Among studies investigating the widest range of noncog- nitive manifestations $[4,7,14-16]$, three symptoms - depression, apathy and anxiety - are consistently among the top four most common behavioral abnormalities in MCI despite the very different study designs, behavioral instruments or MCI diagnostic criteria used. The fourth most common symptom was irritability in four studies $[4,7,14,16]$ and agitation in one $[15]$.

\section{Depression}

Depression is the best-studied neuropsychiatric manifestation of MCI. Four US and four international population-based and five US and four international tertiary center studies have reported data on the prevalence of depression in MCI.

\section{Cross-Sectional Population-Based Studies}

In the mid 1990s the Cardiovascular Health Study's (CHS) Cognition Study ( $\mathrm{n}=3,608$ participants) was nested within the original CHS cohort $(n=5,888)$. Of these subjects 707 met criteria for dementia and 577 for MCI. The diagnosis of MCI required a formal neuropsychological test score 1.5 SD below the age- and education-adjusted norms and absence of dementia per Diagnostic and Statistical Manual of Mental Disorders, fourth edition (DSM-IV) criteria. A subset composed of 362 demented and 320 MCI patients were assessed with the NPI. This study reported the prevalence of depression in community-dwelling MCI subjects to be $20 \%$ relative to $32 \%$ in demented subjects [16].

A smaller population-based study [12] used the NPI to assess the prevalence of depressive symptoms in MCI and demented subjects. Similar to the CHS Cognition Study they based their diagnosis of MCI on a neuropsychologi- 
cal cutoff, but their criteria slightly differed: in addition to those subjects who scored more than $1.5 \mathrm{SD}$ from ageand education-adjusted norms on any neuropsychological measure they also included subjects with scores more than 1 SD on two or more measures. Another difference was the allowance of some degree of functional impairment in the MCI cohort (26\% reported difficulties with basic and 37\% with instrumental activities of daily living). Depression was reported in $16 \%$ of their MCI compared to $22 \%$ of $\mathrm{AD}$ subjects, rates lower than those reported by Lyketsos et al. [16] in the CHS Cognition Study. White race was associated with depression in this study.

There are four international population-based studies on depression in MCI. The Swedish study [18] used the Diagnostic and Statistical Manual of Mental Disorders, third edition revised (DSM-III-R) [32] criteria for the diagnosis of depression. This study based their MCI diagnosis on the MMSE score - they used 1 SD below the ageand education-adjusted mean as a diagnostic cutoff. They reported a relatively low prevalence of depression both in MCI (11\%) and in normal elderly (7\%). The difference did not reach statistical significance. The most common depressive symptom was excessive worrying over trifles. A study from China [26] administered the NPI to subjects with questionable dementia $(\mathrm{CDR}=0.5)$. They reported depressive symptoms to be correlated with functional impairment. The Australian studies $[8,9]$ based their diagnosis of MCI on the criteria of Petersen et al. [1]. They assessed depressive symptoms using two instruments the Goldberg Depression Scale [33] and the DSM-IV [34] criteria for major and minor depression. They evaluated $29 \mathrm{MCI}$ and 522 cognitively normal elderly controls. One of the studies also investigated the neuroimaging correlates of depressive symptoms [9]. The Goldberg Depression Scale demonstrated limited sensitivity for detection of depressive symptoms both in the MCI and the normal control groups (prevalence in $\mathrm{MCI}=3 \%$ and normal controls $=2 \%$ ). Using the DSM-IV criteria resulted in superior sensitivity in diagnosing major depression in $17 \%$ of $\mathrm{MCI}$ and $4 \%$ of the control group. There was no correlation between the presence of major or minor depression and the predefined regions of interest (ventricle size, lobar size, intracranial volume, amygdala or hippocampal volume and white matter lesions) on magnetic resonance imaging [9].

The international multicenter Investigation in the Delay to Diagnosis of AD with Exelon (InDDEX) trial [4] recruited over 1,000 MCI subjects and assessed the prevalence of psychopathology using the NPI. They based their diagnosis of $\mathrm{MCI}$ on one test for delayed verbal re- call and on the CDR scale. The InDDEX trial [4] systematically excluded patients with depression. Potential trial enrollees with a diagnosis of major depression, a Hamilton Depression Rating Scale $>13$ [35] or the presence of sadness on item 1 of the Hamilton Depression Rating Scale were excluded. A low rate of progression to $A D$ was observed in this study. The InDDEX estimate for depression prevalence in MCI assessed with the NPI was over $45 \%$ [4].

\section{Tertiary Center Studies}

Two tertiary center studies utilized the NPI for behavioral assessments in their research cohorts. The study by Hwang et al. [14] reported the prevalence of depression in MCI to be $39 \%$, which was significantly higher than $8 \%$ observed in normal controls. The larger study by Geda et al. [7] reported the substantially lower rate of $9 \%$ for depressive symptoms in MCI, which was not statistically different from the rate in normal controls. The inconsistent results stem most likely from methodological differences between these studies created by the different MCI diagnostic criteria used. Hwang et al. [14] used a cutoff of $1.5 \mathrm{SD}$ from age- and education-adjusted norms on a neuropsychological test while Geda et al. [7] used a clinical rationale based on the Petersen criteria and thus may have included some MCI subjects with milder cognitive impairment than subjects in Hwang et al. [14]. A second potential contributor to this discrepancy is the exclusion of normal controls and MCI subjects who have concomitant untreated depression from the research database that Geda et al. [7] used to identify their MCI sample.

Another tertiary center study [15] used data collected with the Consortium to Establish a Registry for Alzheimer's Disease Behavioral Rating Scale for Dementia (CERAD BRSD) [36]. They reported the highest prevalence of depression among patients with MCI reported thus far. They observed depressive symptoms in 53\% of their MCI subjects. The most common depressive symptoms were hopelessness and crying spells. Their definition of MCI was identical to the one used by Hwang et al. [14]. When splitting the MCI cohort into amnestic and nonamnestic MCI the authors found that amnestic MCI patients were more likely to suffer from crying spells relative to the nonamnestic ones.

\section{Longitudinal Studies}

The study by Barnes et al. [13] used CHS data to establish whether depression is a risk factor for future cognitive decline. The authors analyzed longitudinal data based on the Center for Epidemiological Studies Depres- 
sion Scale [37] from 2,220 normal subjects of whom 13\% (or 296 subjects) developed MCI during a 6-year followup. At baseline normal elderly who were depressed were more often female, less educated, older and had more cerebrovascular disease. They were also more likely to receive a diagnosis of MCI at follow-up - the unadjusted odds for diagnosis of MCI increased by $40 \%$ in those with low and over $100 \%$ in those with moderate/high depression relative to the ones without depression. The odds remained unchanged after adjusting for vascular risk factors.

Another longitudinal population-based study [29] used the CDR scale to qualify subjects as normal (CDR = $0)$ or questionable $\mathrm{AD}(\mathrm{CDR}=0.5)$. They used a semistructured interview to obtain information about psychosis, depression, agitation and passivity [38]. They reassessed the 165 patients 3 years later and based on that CDR score they divided their cohort into three main groups: controls (CDR $=0$ at baseline and follow-up, $\mathrm{n}=$ 32), stable questionable $\mathrm{AD}(\mathrm{CDR}=0.5$ at baseline and follow-up, $\mathrm{n}=90)$ and converters (CDR $=0.5$ at baseline but who subsequently met NINCDS-ADRDA criteria [39] for $A D, n=22$ ). Nineteen subjects did not fall into any of these categories. Both converters and the stable questionable $\mathrm{AD}$ groups endorsed significantly more depressive symptoms (46 and $43 \%$, respectively) relative to the control group (16\%). The most commonly reported depressive symptoms were fatigue and difficulty sleeping. Depressive symptoms were associated with future cognitive decline.

A tertiary center study by Li et al. [19] administered the Hamilton Depression Rating Scale [35] to 146 cognitively normal elderly and $19 \mathrm{MCI}$ patients who were seen in follow-up 2-12 months after initial assessment. Twenty percent of the normal controls declined to MCI or dementia. Nine MCI subjects were diagnosed with AD in follow-up. The prevalence of depression at baseline was $16 \%$ in the controls and $29 \%$ in the MCI group. At followup $14 \%$ of the controls and $28 \%$ of the MCI subjects endorsed depressive symptoms. The incidence of depression in the MCI group was 11.7/100 person-years. The study also reported a very high resistance of depressive symptoms to antidepressant treatment in the MCI group $(60 \%)$.

Two international studies utilized the Montgomery and Asberg Depression Rating Scale (MADRS) [40]. The French study [21] based their definition of MCI on memory complaints and impaired delayed recall (inability to recall three out of three items after delay) on the MMSE test or an Isaacs-set test score less than 29 [41]. They did not find difference in the prevalence of depressive symptoms between MCI subjects who converted to dementia and those who did not. A Polish study [24] diagnosed $\mathrm{MCI}$ by the Petersen criteria and also required a CDR score of 0.5. Multiple domain amnestic MCI patients had significantly higher MADRS baseline scores relative to single domain amnestic MCI. After a mean 3-year followup period 63 of the total of 105 patients (including MCI and controls) declined cognitively. More severe depression (higher MADRS score) at baseline was a significant predictor for progression to dementia. Gabryelewicz et al. [25] also published analyses using DSM-IV diagnostic data on minor and major depression in their MCI cohort. Almost half of all MCI patients met DSM-IV criteria for depression: $27 \%$ suffered from minor and $20 \%$ from major depressive disorder. The most common symptoms were sadness, poor concentration, inner tension, pessimistic thoughts, lassitude and reduced sleep. According to Modrego and Ferrández [10] MCI subjects diagnosed clinically by the Petersen criteria who score in the depressed range on the Geriatric Depression Scale [42] at baseline are 2.6 times more likely to decline to dementia during follow-up (relative risk 2.6; 95\% CI 1.8-3.6). The poorer response to antidepressant therapy in converters relative to nonconverters ( $71 \%$ resistance to therapy in MCI converters) seen in this study is consistent with the data by Li et al. [19], who observed $60 \%$ resistance to antidepressant therapy in MCI relative to the cognitively normal elderly. Taken together these two studies suggest that depression secondary to $\mathrm{AD}$ pathology is persistent and possibly refractory to therapy.

\section{Cognitive Impairment Meeting MCI Criteria in \\ Elderly Patients with Depression}

Adler et al. [43] enrolled 34 depressed elderly of whom 18 patients met MCI criteria based on a score less than 46 on the Structured Interview for the Diagnosis of Dementia of the Alzheimer's type, Multi-Infarct Dementia and Dementias of other Aetiology [44]. All patients were treated for depression and reassessed 6 months later. While the mean cognitive scores remained unchanged, the Hamilton Depression Rating Scale scores improved in the group as a whole. Of the 15 patients with baseline diagnosis of MCI who were seen in follow-up 12 continued to meet MCI criteria.

A study by Lee et al. [45] enrolled 142 elderly patients with major depression by DSM-IV criteria, instituted antidepressant therapy and reassessed them a year later. Of the 67 depressed patients who remitted, 55\% had amnestic MCI at baseline (1.5 SD below the age- and education- 
adjusted scores on one or more memory tests) and $60 \%$ of these continued to exhibit MCI despite antidepressant therapy. Diagnosis of MCI at follow-up was associated with age, female gender, low education and instrumental functional impairment at baseline.

\section{New-Onset Depression and MCI in Cognitively \\ Normal Elderly}

A recent prospective cohort study by Geda et al. [6] followed 840 cognitively normal elderly for an average of 3.5 years (range 0.4-12.8). Seventeen percent developed depression during follow-up. Thirteen percent of those who received diagnosis of depression also met criteria for amnestic MCI. Among those who did not develop depression only $5 \%$ met criteria for amnestic MCI. Those who had new-onset depression (i.e. no past medical history of depressive episodes) had a hazard ratio for cognitive decline of 4.5 (95\% CI 1.9-10.9) relative to those who were never depressed, suggesting that newly diagnosed depressive disorder in the elderly is a significant risk factor for cognitive decline. The observed association was further strengthened by the presence of one or two apolipoprotein epsilon 4 alleles (HR 5.1; 95\% CI 1.9-13.6).

\section{Apathy}

Apathy is the most prevalent neuropsychiatric symptom in $\mathrm{AD}$ [28]. It commonly starts during the MCI stage and progressively increases as AD progresses [27]. Two population-based, six tertiary center studies and one clinical trial have investigated apathetic symptoms in MCI.

\section{Cross-Sectional Population-Based Studies}

Two population-based studies and the InDDEX trial used the NPI to measure apathy in MCI. The CHS Cognition Study and the InDDEX trial $[4,16]$ reported 32-36\% of the MCI subjects suffered from apathy. In the CHS Cognition Study apathy was the most common behavioral symptom among MCI subjects, while in the InDDEX trial it was fourth after depression, irritability and agitation.

A study from China by Lam et al. [26] reported associations between apathy severity and depressive symptoms as well as apathy and functional impairment (more difficulty with instrumental activities of daily living).

\section{Tertiary Center Studies}

The two NPI-based tertiary center studies report somewhat different apathy prevalence data in MCI: 39\% in Hwang et al. [14] versus $11 \%$ in Geda et al. [7]. The potential reason for the inconsistency was noted above (see section 'Diagnostic Criteria for MCI'). Apathy was the most common symptom in Hwang et al. [14] and was the second most prevalent symptom after irritability in the study by Geda et al. [7]. Using the CERAD BRSD Lopez et al. [15] ascertained the prevalence of anhedonia to be $40 \%$ in all MCI subjects (31\% in amnestic and $44 \%$ in nonamnestic $\mathrm{MCI}$ - a rate very similar to that reported by Hwang et al. [14]. In a cross-sectional study of clinically defined MCI subjects by Petersen criteria using the Frontal System Behavioral Scale [46], Ready et al. [11] reported apathy among MCI subjects to be as prevalent as apathy in $\mathrm{AD}$ patients.

\section{Longitudinal Studies}

One longitudinal population-based study [29] assessed passivity with a semistructured interview of the patient and informant. Subjects who at baseline were $\mathrm{CDR}=0.5$ but at 3-year follow-up met criteria for $\mathrm{AD}$ endorsed significantly more passivity at baseline $(27 \%)$ relative to the control subjects who were $\mathrm{CDR}=0$ both at baseline and follow-up (3\%). Thirteen percent of those who scored $\mathrm{CDR}=0.5$ at both baseline and follow-up showed symptoms of passivity, however, this rate did not differ significantly from the one reported in controls. Loss of interest was the most commonly reported passive symptom.

Two French longitudinal studies [21,22] both used the Apathy Inventory [47]. Their MCI criteria were based on memory complaints and impaired delayed recall on the MMSE memory items (two out of three items or less) or an Isaacs-set test score less than 29. The researchers reported baseline apathy prevalence in MCI subjects who converted to dementia in follow-up to be $59 \%$ versus $38 \%$ in MCI subjects who remained stable. This difference did not survive multiple comparison correction. At follow-up $92 \%$ of the demented group had apathy versus $27 \%$ of the stable MCI subjects. The other study [22] investigated the associations between apathy and demographic, neuropsychological and psychiatric factors. The authors reported a higher frequency of apathy in those with history of psychiatric disorder. The MCI group with apathy performed worse on tests of memory and executive control.

\section{Anxiety}

\section{Cross-Sectional Population-Based Studies}

Both the CHS Cognition Study [16] using the NPI and the Swedish Kungsholmen project study [18] using DSM- 
III-R criteria for diagnosis of anxiety reported anxiety frequencies of $10 \%$ of their MCI sample. The Kungsholmen diagnosis of MCI was based on neuropsychological scores of 1 SD or more below the age- and education-adjusted means. That study also compared the rates of anxiety in MCI and normal controls and reported significantly higher rates in MCI relative to elderly controls (10 vs. 4\%). Kumar et al. [8] used the Goldberg Anxiety Scale [33] for assessment of anxiety and the consensus Petersen criteria for diagnosing MCI and applied them to 29 MCI subjects. The reported rate for anxiety in MCI was not significantly greater than the rate observed in normal controls ( 3 vs. $2 \%$ ) and is much smaller relative to the other two population-based studies discussed above, possibly because of different instrument sensitivity for diagnosing anxiety or the small sample size. The InDDEX trial reported a very high prevalence of anxiety (45\%) among patients in their large international multicenter MCI cohort [4].

\section{Tertiary Center Studies}

There was a discrepancy between the 2 tertiary center studies. Hwang et al. [14] report the prevalence of anxiety among tertiary center MCI patients to be $25 \%$. Geda et al. [7] observed anxiety in only $11 \%$ of their MCI population. Using the CERAD BRSD Lopez et al. [15] found anxiety features in $49 \%$ of their large tertiary MCI cohort. As mentioned previously these differences may be due to the different enrollment criteria for the MCI cohort.

\section{Longitudinal Studies}

We identified only one longitudinal study addressing anxiety in MCI [22]. Robert et al. [22] used the Goldberg Anxiety Scale $[33,48]$ to assess anxiety at baseline and at 1-year follow-up in $216 \mathrm{MCI}$ patients and reported no significant difference in the prevalence of anxiety between MCI converters and MCI nonconverters at baseline (2.9 vs. 2.6\%). Follow-up anxiety data were not reported.

\section{Psychosis}

\section{Cross-Sectional Population-Based Studies}

The CHS Cognition Study [16] and the InDDEX trial [4] used the NPI to assess the prevalence of hallucinations and delusions. The CHS Cognition Study reported the prevalence of delusions and hallucinations among their $320 \mathrm{MCI}$ subjects to be 3 and 1\%, respectively. The InDDEX trial found slightly higher prevalence rates of $6 \%$ for delusions and $2 \%$ for hallucinations. Using DSM-
III-R criteria for psychosis, the Swedish Kungsholmen project diagnosed 3\% of their MCI cohort with psychosis [18]. This study was the only one comparing the frequency of psychosis in MCI and normal elderly and found no significant difference. Higher rates among MCI patients (10\%) were reported by only one study using the Behavioral Symptom Rating Scale [12, 49].

\section{Tertiary Center Studies}

Both US NPI studies cite very low frequency of hallucinations (0\%) and delusions (0-4\%) in MCI [7, 14]. The CERAD BRSD assessment for psychotic symptoms in the University of Pittsburg cohort disclosed somewhat higher rates of both hallucinations (4\%) and delusions (14\%) [15].

\section{Longitudinal Studies}

One study used the CERAD BRSD in longitudinal follow-up of 288 patients of whom 49 were MCI and the rest were AD [17]. The mean follow-up was 22 months (range 5-44). The authors reported only the global incidence for psychotic symptoms for the whole group so the exact incidence for the MCI subgroup remains unknown. During follow-up 82 subjects developed psychosis (46 misidentification syndromes, 25 paranoia and 11 both). The incidence for psychosis in general was 19/100 person-years whereas for misidentification delusions the rate was 12/100 person-years and for paranoid delusions 7/100 person-years. The authors reported an association between lower MMSE scores and onset of psychotic symptoms. Subjects with misidentification symptoms tended to have longer disease duration and lower MMSE scores relative to nonpsychotic patients. Females and depressed patients were more likely to experience both paranoid delusions and misidentification syndromes [50].

\section{Disinhibition}

The rates of disinhibition as measured by the NPI among MCI patients in one large population-based study [16] and the InDDEX clinical trial [4] ranged from 3 to $10 \%$. Higher rates of disinhibition have been reported by the tertiary center studies (2-18\%) albeit these rates were not significantly different from those observed in normal elderly in both studies [7, 14]. Disinhibition was not a common symptom in MCI when measured with the Frontal Systems Behavioral Scale [11]. 


\section{Agitation}

The CHS Cognition study reported that $11 \%$ of their MCI patients experienced agitation [16]. The InDDEX trial reported 35\% [4]. Using the Behavioral Symptoms Rating Scale, the population-based study by Chan et al. [12] found the rate of agitation among MCI to be $25 \%$. The tertiary center study by Hwang et al. [14] reports a prevalence of $18 \%$, consistent with the rates found in the community. Geda et al. [7] report only $4 \%$ of their MCI cohort suffered from agitation. This rate was not significantly different from that of normal controls. The CERAD BRSD uncovered agitation in $38 \%$ of 228 MCI subjects in the tertiary center study by Lopez et al. [15].

One longitudinal population-based study [29] assessed agitation with a semistructured interview of the patient and informant. Subjects who at baseline were CDR $=0.5$ but at 3-year follow-up met criteria for AD and subjects who were $\mathrm{CDR}=0.5$ both at baseline and follow-up suffered from significantly more agitation at baseline (36 and 18\%, respectively) relative to subjects who were $\mathrm{CDR}=0$ both at baseline and follow-up (6\%). Irritability was the most commonly reported personality change. Agitation was associated with faster functional decline.

\section{Euphoria, Aberrant Motor Behavior and Irritability}

Only the NPI-based studies investigated the presence of euphoria, irritability and aberrant motor behavior in MCI. In population-based MCI samples, the frequencies of euphoria, aberrant motor behavior and irritability were $1-5,4-8$ and $15-44 \%$, respectively, where the higher rates came from the clinical trial sample $[4,16]$. The smaller tertiary center-based NPI studies report none of their subjects experienced euphoria or aberrant motor behavior and $13-29 \%$ showed symptoms of irritability [7, 14].

\section{Discussion}

Neuropsychiatric manifestations are very common in MCI, occurring in $35-75 \%$ of patients (table 3). The most common behavioral symptoms are apathy, anxiety, depression, irritability and agitation. Least common are euphoria, hallucinations, disinhibition and aberrant motor behavior (table 3). The observed differences in the reported incidence and prevalence rates are at least partly accounted for by the different sampling methods (popula- tion-based vs. tertiary care center vs. clinical trial population) and in some instances also the exclusion of subjects with depressive symptoms [4, 6, 7, 24, 25]. Depression, anxiety and agitation were less prevalent, while aberrant motor behavior and irritability were more common in population-based versus tertiary care center studies. The heterogeneity in MCI diagnostic criteria and behavioral assessment instruments (table 1) undoubtedly contributed further to the significant variability in the reported incidence and prevalence rates.

Neuropsychiatric symptoms in MCI are associated with declining cognitive and functional ability $[4,11,12$, $21,29]$. Depression, apathy and agitation have been shown to increase the likelihood of later conversion to $\mathrm{AD}[10$, $22,29]$. These data suggest that certain neuropsychiatric features could serve as clinical indicators of the presence of prodromal disease. Other important observations were that MCI patients (relative to cognitively normal elderly) [19] and particularly the subset of MCI subjects who have incipient dementia demonstrate greater resistance to antidepressant therapy [10].

Several limitations of this study should be acknowledged. First, we reviewed only studies published in the English literature. Second, our ability to compare data from various studies was limited by the heterogeneity in the population sampling methods, diagnostic criteria for MCI and various methods for neuropsychiatric symptom ascertainment that were used. Together the studies provide insight into the frequency and type of behavioral symptoms observed in MCI patients in a variety of settings.

Given the very limited and highly heterogeneous data on neuropsychiatric manifestations in MCI to date, the following research agenda is warranted. Large prospective longitudinal studies that utilize standard MCI diagnostic criteria and neuropsychiatric instruments designed for the cognitively impaired are needed. For the purpose of studying the behavioral features of MCI, subjects with depression at baseline should not be avoided. Such well-designed and executed epidemiological studies of noncognitive symptoms in MCI would advance our understanding of the protective and risk factors for neuropsychiatric features of $\mathrm{MCI}$, their predictive value for future conversion to dementia and whether they could be useful for differentiation among neurodegenerative disorders. Studies of the treatment of noncognitive symptoms in MCI would aid in optimizing therapy for these patients. 


\section{Acknowledgments}

This work was supported by NIA K23 AG026803 (jointly sponsored by NIA, AFAR, The John A. Hartford Foundation, the Atlantic Philanthropies, the Starr Foundation and an anonymous donor to L.G.A.), NIA P50 AG16570 (to J.L.C. and L.G.A.), the Alzheimer's Research Centers of California and the Sidel Kagan Foundation (to J.L.C.).

The search of the literature was conducted with PubMed on December 6, 2006.

\section{References}

$\checkmark 1$ Petersen RC, Doody R, Kurz A, Mohs RC, Morris JC, Rabins PV, Ritchie K, Rossor M, Thal L, Winblad B: Current concepts in mild cognitive impairment. Arch Neurol 2001;58: 1985-1992.

-2 Jicha GA, Parisi JE, Dickson DW, Johnson K, Cha R, Ivnik RJ, Tangalos EG, Boeve BF, Knopman DS, Braak H, Petersen RC: Neuropathologic outcome of mild cognitive impairment following progression to clinical dementia. Arch Neurol 2006;63:674-681.

$\checkmark 3$ Winblad B, Palmer K, Kivipelto M, Jelic V, Fratiglioni L, Wahlund LO, Nordberg A, Backman L, Albert M, Almkvist O, Arai H, Basun H, Blennow K, de Leon M, DeCarli C, Erkinjuntti T, Giacobini E, Graff C, Hardy J, Jack C, Jorm A, Ritchie K, van Duijn C, Visser P, Petersen RC: Mild cognitive impairment - beyond controversies, towards a consensus: report of the International Working Group on Mild Cognitive Impairment. J Intern Med 2004;256:240-246.

$\checkmark 4$ Feldman H, Scheltens P, Scarpini E, Hermann N, Mesenbrink P, Mancione L, Tekin S, Lane R, Ferris S: Behavioral symptoms in mild cognitive impairment. Neurology 2004; 62:1199-1201.

5 Petersen RC, Smith GE, Waring SC, Ivnik RJ, Tangalos EG, Kokmen E: Mild cognitive impairment: clinical characterization and outcome. Arch Neurol 1999;56:303-308.

-6 Geda YE, Knopman DS, Mrazek DA, Jicha GA, Smith GE, Negash S, Boeve BF, Ivnik RJ, Petersen RC, Pankratz VS, Rocca WA: Depression, apolipoprotein E genotype, and the incidence of mild cognitive impairment: a prospective cohort study. Arch Neurol 2006; 63:435-440.

$\checkmark 7$ Geda YE, Smith GE, Knopman DS, Boeve BF, Tangalos EG, Ivnik RJ, Mrazek DA, Edland SD, Petersen RC: De novo genesis of neuropsychiatric symptoms in mild cognitive impairment (MCI). Int Psychogeriatr 2004;16:51-60.

8 Kumar R, Jorm AF, Parslow RA, Sachdev PS Depression in mild cognitive impairment in a community sample of individuals 60-64 years old. Int Psychogeriatr 2006;18:471-480.

$\checkmark 9$ Kumar R, Parslow RA, Jorm AF, Rosenman SJ, Maller J, Meslin C, Anstey KJ, Christensen H, Sachdev PS: Clinical and neuroimaging correlates of mild cognitive impairment in a middle-aged community sample: the personality and total health through life $60+$ study. Dement Geriatr Cogn Disord 2006;21:44-50
10 Modrego PJ, Ferrández J: Depression in patients with mild cognitive impairment in creases the risk of developing dementia of Alzheimer type: a prospective cohort study. Arch Neurol 2004;61:1290-1293.

11 Ready RE, Ott BR, Grace J, Cahn-Weiner DA: Apathy and executive dysfunction in mild cognitive impairment and Alzheimer disease. Am J Geriatr Psychiatry 2003;11: 222-228.

12 Chan DC, Kasper JD, Black BS, Rabins PV: Prevalence and correlates of behavioral and psychiatric symptoms in community-dwelling elders with dementia or mild cognitive impairment: the Memory and Medical Care Study. Int J Geriatr Psychiatry 2003;18:174182.

13 Barnes DE, Alexopoulos GS, Lopez OL, Williamson JD, Yaffe K: Depressive symptoms, vascular disease, and mild cognitive impairment: findings from the Cardiovascular Health Study. Arch Gen Psychiatry 2006;63: 273-279.

14 Hwang TJ, Masterman DL, Ortiz F, Fairbanks LA, Cummings JL: Mild cognitive impairment is associated with characteristic neuropsychiatric symptoms. Alzheimer Dis Assoc Disord 2004;18:17-21.

15 Lopez OL, Becker JT, Sweet RA: Non-cognitive symptoms in mild cognitive impairment subjects. Neurocase 2005;11:65-71.

16 Lyketsos CG, Lopez O, Jones B, Fitzpatrick AL, Breitner J, DeKosky S: Prevalence of neuropsychiatric symptoms in dementia and mild cognitive impairment: results from the cardiovascular health study. JAMA 2002; 288:1475-1483.

17 Wilkosz PA, Miyahara S, Lopez OL, Dekosky ST, Sweet RA: Prediction of psychosis onset in Alzheimer disease: the role of cognitive impairment, depressive symptoms, and further evidence for psychosis subtypes. Am J Geriatr Psychiatry 2006;14:352-360.

18 Forsell Y, Palmer K, Fratiglioni L: Psychiatric symptoms/syndromes in elderly persons with mild cognitive impairment: data from a cross-sectional study. Acta Neurol Scand Suppl 2003;179:25-28.

19 Li YS, Meyer JS, Thornby J: Longitudinal follow-up of depressive symptoms among normal versus cognitively impaired elderly. Int J Geriatr Psychiatry 2001;16:718-727.

20 Folstein MF, Folstein SE, McHugh PR: MiniMental State: a practical method for grading the cognitive state of patients for the clinician. J Psychiatr Res 1975;12:189-198.
21 Robert PH, Berr C, Volteau M, Bertogliati C, Benoit M, Mahieux F, Legrain S, Dubois B: Neuropsychological performance in mild cognitive impairment with and without apathy. Dement Geriatr Cogn Disord 2006;21: 192-197.

22 Robert PH, Berr C, Volteau M, Bertogliati C, Benoit M, Sarazin M, Legrain S, Dubois B: Apathy in patients with mild cognitive impairment and the risk of developing dementia of Alzheimer's disease: a one-year followup study. Clin Neurol Neurosurg 2006;108: 733-736.

23 Morris JC: The Clinical Dementia Rating (CDR): current version and scoring rules. Neurology 1993;43:2412-2414.

24 Gabryelewicz T, Styczynska M, Luczywek E, Barczak A, Pfeffer A, Androsiuk W, Chodakowska-Zebrowska M, Wasiak B, Peplonska $\mathrm{B}$, Barcikowska $\mathrm{M}$ : The rate of conversion of mild cognitive impairment to dementia: predictive role of depression. Int J Geriatr Psychiatry 2007;22:563-567.

25 Gabryelewicz T, Styczynska M, Pfeffer A, Wasiak B, Barczak A, Luczywek E, Androsiuk W, Barcikowska M: Prevalence of major and minor depression in elderly persons with mild cognitive impairment: MADRS factor analysis. Int J Geriatr Psychiatry 2004; 19:1168-1172.

$\checkmark 26$ Lam LC, Tam CW, Chiu HF, Lui VW: Depression and apathy affect functioning in community active subjects with questionable dementia and mild Alzheimer's disease. Int J Geriatr Psychiatry 2007;22:431-437.

27 Apostolova LG, Cummings JL: Psychiatric manifestation in dementia. Continuum Lifelong Learning Neurol 2007;13:165-179.

28 Cummings JL: The Neuropsychiatry of Alzheimer's Disease and Related Dementias. London, Dunitz, 2003.

29 Copeland MP, Daly E, Hines V, Mastromauro C, Zaitchik D, Gunther J, Albert M: Psychiatric symptomatology and prodromal Alzheimer's disease. Alzheimer Dis Assoc Disord 2003;17:1-8.

30 Petersen RC: Mild cognitive impairment. Continuum Lifelong Learning Neurol 2007; 13:13-36.

31 Cummings JL: The Neuropsychiatric Inventory: assessing psychopathology in dementia patients. Neurology 1997;48:S10-S16.

32 Association AP: Diagnostic and Statistical Manual of Mental Disorders, ed 3 revised (DSM-III-R). Washington, American Psychiatric Association, 1987. 
33 Goldberg D, Bridges K, Duncan-Jones P, Grayson D: Detecting anxiety and depression in general medical settings. BMJ 1988 ; 297:897-899.

34 Association AP: Diagnostic and Statistical Manual of Mental Disorders, ed 4 (DSM-IV), Text Revision. Washington, American Psychiatric Association, 2000.

35 Hamilton M: A rating scale for depression. J Neurol Neurosurg Psychiatry 1960;23:5662.

-36 Tariot PN: CERAD behavior rating scale for dementia. Int Psychogeriatr 1996;8(suppl 3): 317-320; discussion 351-354.

-37 Andresen EM, Malmgren JA, Carter WB, Patrick DL: Screening for depression in well older adults: evaluation of a short form of the CES-D (Center for Epidemiologic Studies Depression Scale). Am J Prev Med 1994;10: 77-84.

-38 Hughes CP, Berg L, Danziger WL, Coben LA, Martin RL: A new clinical scale for the staging of dementia. Br J Psychiatry 1982; 140:566-572.
9 McKhann G, Drachman D, Folstein M, Katzman R, Price D, Stadlan EM: Clinical diagnosis of Alzheimer's disease: report of the NINCDS-ADRDA Work Group under the auspices of Department of Health and Human Services Task Force on Alzheimer's Disease. Neurology 1984;34:939-944.

40 Montgomery SA, Asberg M: A new depression scale designed to be sensitive to change. Br J Psychiatry 1979;134:382-389.

41 Isaacs B, Kennie AT: The Set test as an aid to the detection of dementia in old people. Br J Psychiatry 1973;123:467-470.

42 Yesavage JA: Geriatric Depression Scale. Psychopharmacol Bull 1988;24:709-711.

43 Adler G, Chwalek K, Jajcevic A: Six-month course of mild cognitive impairment and affective symptoms in late-life depression. Eur Psychiatry 2004;19:502-505.

44 Zaudig M, Hiller W: Strukturiertes Interview für die Diagnose einer Demenz vom Alzheimer Typ, der Multiinfarkt- (oder vaskulären) Demenz und Demenzen anderer Ätiologie nach DSM-III-R, DSM-IV und ICD10 (SIDAM). Bern, Huber, 1996.

45 Lee JS, Potter GG, Wagner HR, WelshBohmer KA, Steffens DC: Persistent mild cognitive impairment in geriatric depression. Int Psychogeriatr 2007;19:125-135.
46 Grace J, Malloy P: The Frontal Systems Behavioral Scale Manual. Odessa, Psychological Assessment Resources, 2002.

47 Robert PH, Clairet S, Benoit M, Koutaich J, Bertogliati C, Tible O, Caci H, Borg M, Brocker P, Bedoucha P: The apathy inventory: assessment of apathy and awareness in Alzheimer's disease, Parkinson's disease and mild cognitive impairment. Int J Geriatr Psychiatry 2002;17:1099-1105.

48 Goldberg DP, Hillier VF: A scaled version of the General Health Questionnaire. Psychol Med 1979;9:139-145.

49 Rabins PV: The validity of a caregiver rated brief Behavior Symptom Rating Scale (BSRS) for use in the cognitively impaired. Int J Geriatr Psychiatry 1994;9:205-210.

50 Steinberg M, Corcoran C, Tschanz JT, Huber C, Welsh-Bohmer K, Norton MC, Zandi P, Breitner JC, Steffens DC, Lyketsos CG: Risk factors for neuropsychiatric symptoms in dementia: the Cache County Study. Int J Geriatr Psychiatry 2006;21:824-830. 